\title{
A WOODEN DOOR DATES BACK TO 13 H. / 19 A.D. AT THE MUSEUM OF FINE ARTS IN TASHKENT
}

\author{
Ebaid, Sh. ${ }^{1} \&$ Gpil, M. ${ }^{1}$ \\ ${ }^{1}$ Lecture in Islamic dept., Faculty of Archaeology, Cairo Univ. \\ e-mail: Sheblebaid@hotmail.com
}

\begin{abstract}
Many of architectural buildings in Central Asia include models of wooden works, some wooden doors still in their places, others transferred into different museums for protecting them from damage or as result of the destruction of the building where they were fixed. This study aims to deal with one of wooden doors which dated back to 13th A.H-19th A.D kept in the museum of Fine Arts in Tashkent the case of study which attributed to the city of khiva under the rule of Ushtarkhanid and Manghit. In addition it's a unique model of wooden doors through it we can follow the industrial and decorative development of the industry of doors in khiva during that period and to what extent it was affected by the same industry during the Timurid and Safawid periods before it. The door characterized by its executed ornaments which came as a continuation of the Timurid style in its realistic and abstract floral decorations - the style of Arabesque.
\end{abstract}

Keywords: Wooden door, Museum of fine arts, Tashkent, Khiva, Floral decoration

\section{Introduction}

The door composed of one shutter, pl. (1) and it contains three central rectangular panels, pl. (2) fig. (1), but the upper and the lower panels are square, surrounded by decorative braids. The door is decorated with Natural floral ornaments and others abstract in Arabesque style carried out in high relief carving. Its noticeable through the constructions that the general form which composed of three panels rectangular in shape was the most used form in the decoration of door inside the buildings of central Asia, two of the panels are narrow up and down the third panel extended vertically between the two - as shown through our study. This form represents a continuation of the doors during the
Timurid period "771 H / 906 A.D - 1369 H / 1500 A.D" and Shaybanid "906 AH/1008 A.D - 1500 H / 1599 A.D" and continued till the period of the study such as in the door graving vault in the complex of Ahmed Yasavi at western Turkistan "797 H / 1394 A.D", plate (3) the door of the complex of Qutham Ibn Abbass at Shah Zinda in Samarqand "807 H / 1404 A.D", plate (4), which decorated with floral motifs and geometrical shapes, the doors of Shirdar Madra a in Samarqand "1029-1045 H / 1619-1635 A.D", and the doors of Telacarey in Samarqand "1057-1070 H /1647-1659 A.D" [1] These doors were executed also in the doors of the constructions in the paintings of 
temporary manuscripts' which attributed to the same area such as the tale of Bohram Gur in the black palace from khamsa Nizami manuscript attributed to Herat Kept in the British Museum -London- dated back to the end of $9 \mathrm{H} /$ 15 A.D century no. or 259000 [2] The door - the case of the study - resembles the doors dated back to the period of "8 H-14 AD / $10 \mathrm{H}$ - 16 A.D", all of them have the tri- division on doors and the Industrial \& decorative styles which depend on Timurid style that spread in all applied arts in general and in book covers and pottery in particular, this division continued till "12-13 H / 18-19 A.D".

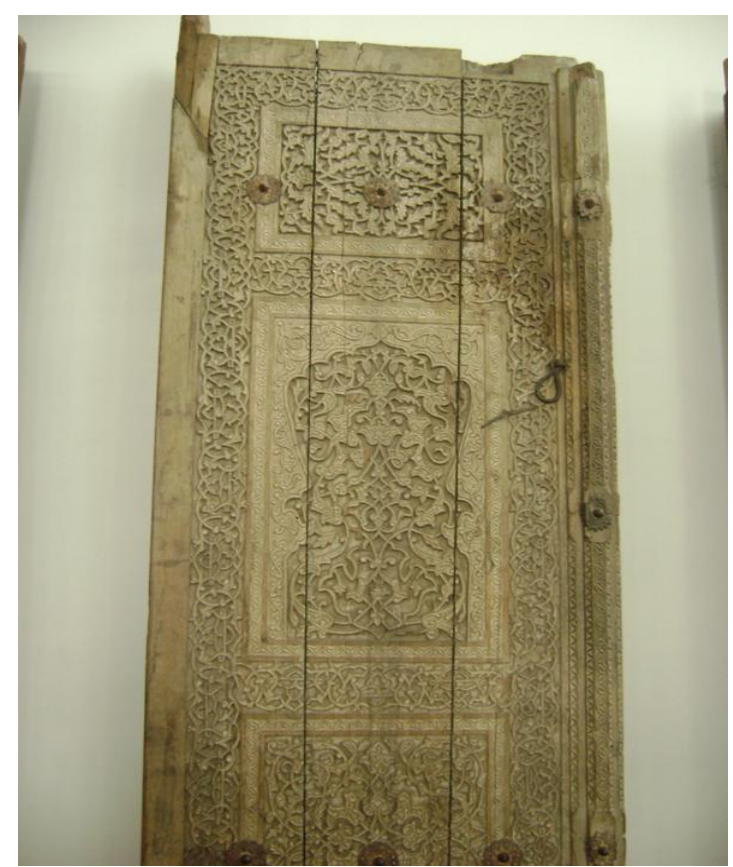

Plate (1) a wooden Door at museum of Fine Arts in Tashkent.

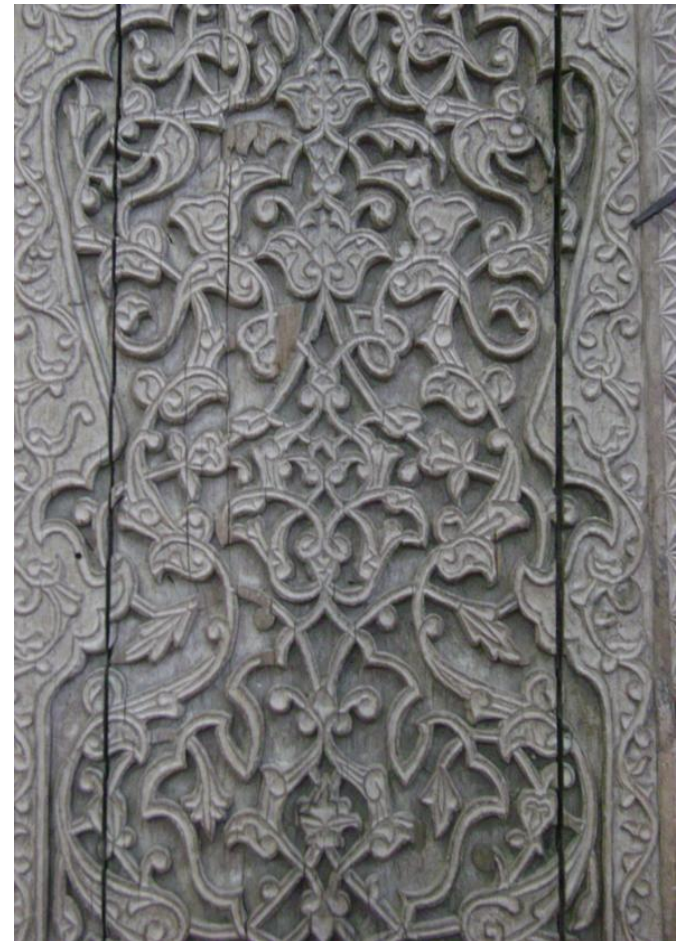

Plate (2) the central rectangular panel of a wooden door.

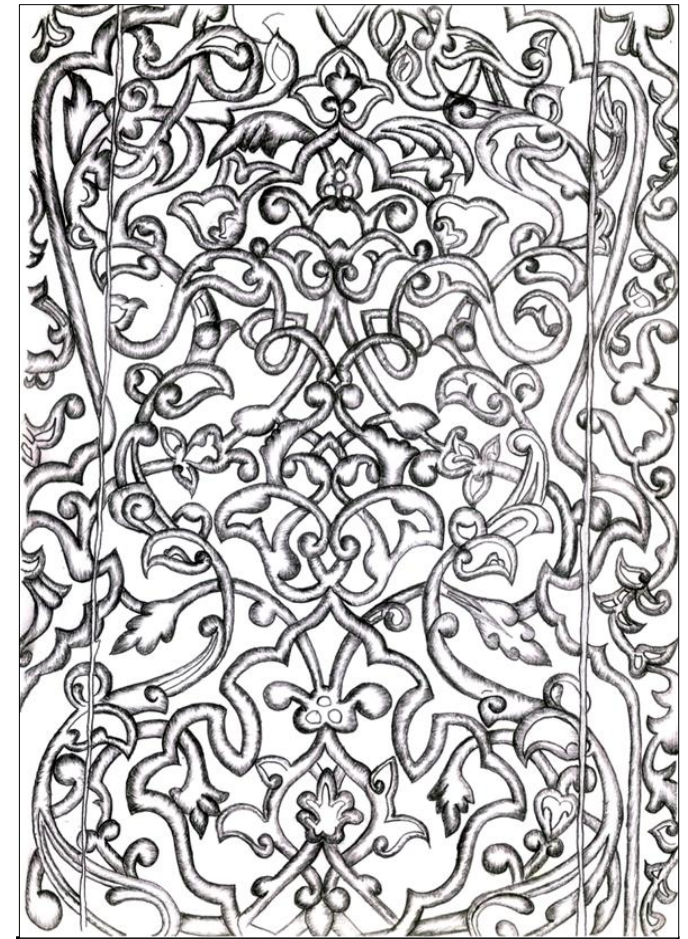

Figure (1) abstract floral decoration of a wooden door. 


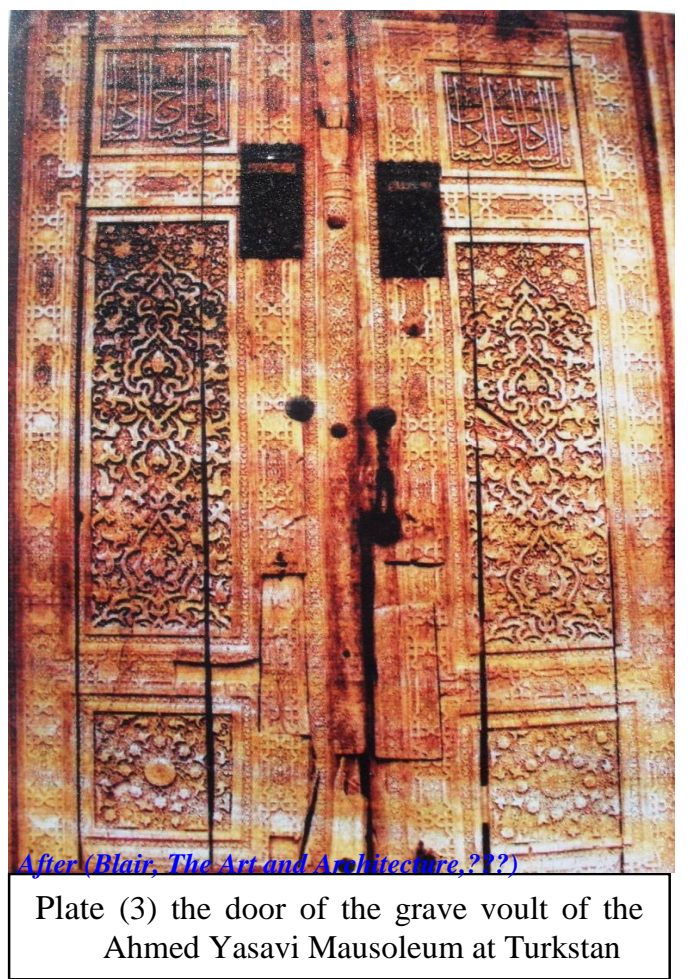

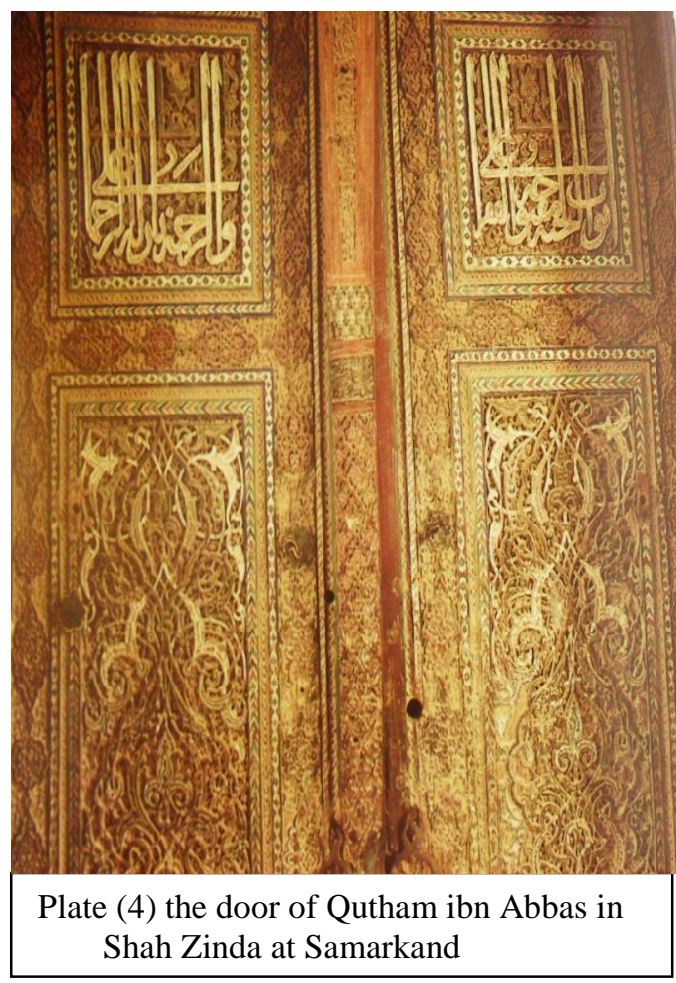

\section{Raw material}

The availability of trees in Central Asia had a significant impact on the production of various woodworks. The best types of trees which were used in the industry and wood carving were Walnut, Al-dalb, ash ,juniper "a type of pine trees", raspberry ,apricot ,beech and oak and pine [3], most of wooden artifacts which exist in Western Turkistan were made of local wood [4].

\section{Manufacturing techniques}

The wooden door which we study was carved in high-relief, in this technique the decorative motifs raised a little than the ground, where the decorations here executed in floral ornaments which were a continuation of Timurid style carried out in natural way consists of branches and leaves as well as abstract motifs deprived from architectural motifs such as arches, multi lopped as in the central panel of the door. The manufacturing technique in this door is a continuation of the door in architectural buildings during previous periods. Carved woods which dated back to the early Mongol period and attributed to the second half of "7-8 H / 13-early 14 A.D", century one of the rare artifacts in Iran and western Turkistan such as the door of Bayazid Bastam mosque dated back to "707-709 H / 1307-1309 A.D", plate (5), carved in beautiful way decorated with inscriptions as well as floral and geometrical ornaments interlaced together which resemble the temporary ornaments on stone and stucco in Iran [5]. After these doors come the door of the great mosque in Nagan "711 H / 1311 A.D", which contain rectangular panels decorated with geometrical branches carry round leaves [6], in addition we find another collection of column of carved wood in Jummi mosque in khiva, "13 H / 19 A.D" [7]. At the second half of $8 \mathrm{H} /$ 14A.D century the area of western Turkistan reached a high level in carving wood, we have a collection of wooden artifacts which were attributed to Timurid period, such as many doors from the period of Timur made by the artists of Turkistan for example ,a door in the mosque of Ahmed Yasavi in Turkistan the main door dated back to "800 H / 1397 A.D", while the inner door dated back to " $798 \mathrm{H} / 1395$ A.D" [8]. The floral decoration in the main panel remind us with the Quran stand plate (6) in metropolitan Museum 
in New York [9].Turkistan contains a series of doors which dated back to Timurid period such as the door of grave vault of the complex of Ahmed Yasavi in Turkistan "797 H / 1394 A.D", door of Shah Zendi "5-13 H / 11-19 A.D". Its decorations are considered good examples of carved wood as it was made of walnut wood and covered with multicolored paintings, the door of the complex of Qatham Ibn Abbass at Shah Zendi in Samarqand "807 H / 1404 A.D" Which used the high - relief in its decorations, [10], the door of Guri - amir in Samarqand "807 H / 1404 A.D" kept in Hermitage museum in Sant Petersburg, its decorations executed in high - relief too as well as inlaying with ivory [11]. Artists of Timurid period used the same techniques which used by Mongol artists, this shown in a door dated back to the beginning of "9 $\mathrm{H} / 15$

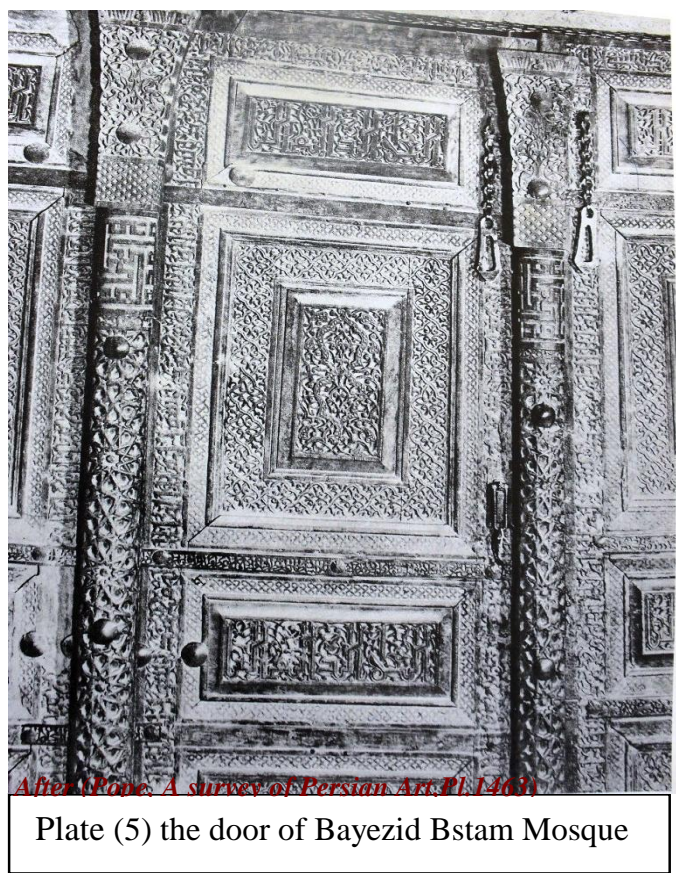

\section{Decorations}

Decorative styles used on the wooden door characterized by the variety of its decorations which came as a reflection of decorative development in Timurid art in general at the end of " $8 \mathrm{H} /$ 14 A.D" century and continued till the period of our door-in using natural floral motifs such as floral leaves which we
A.D", century' [5], at the madrasa of Ulg Beg "820 H / 1417 A.D", as well as a door kept in metropolitan museum from Kokand, the main panel executed in highrelief with interlaced forms composed of floral and flower branches decorations carrying big size palmettes surrounded by branches of leaves in high-relief, This door was painted before which was a habit in western Turkistan, we can notice through the remained colors that the ground was painted in blue and the decorations in red, green ,brown and gold colors, By the comparison of wooden artifacts which dated back to "9 H / 15 A.D" such as frames, windows, doors of the tomb of Timur in Samarqand we can decide that our door dated back to the end of "11-13 H / 17-19 A.D", Thus khiva, Tashkent and Kokand become the main centers of this technique.

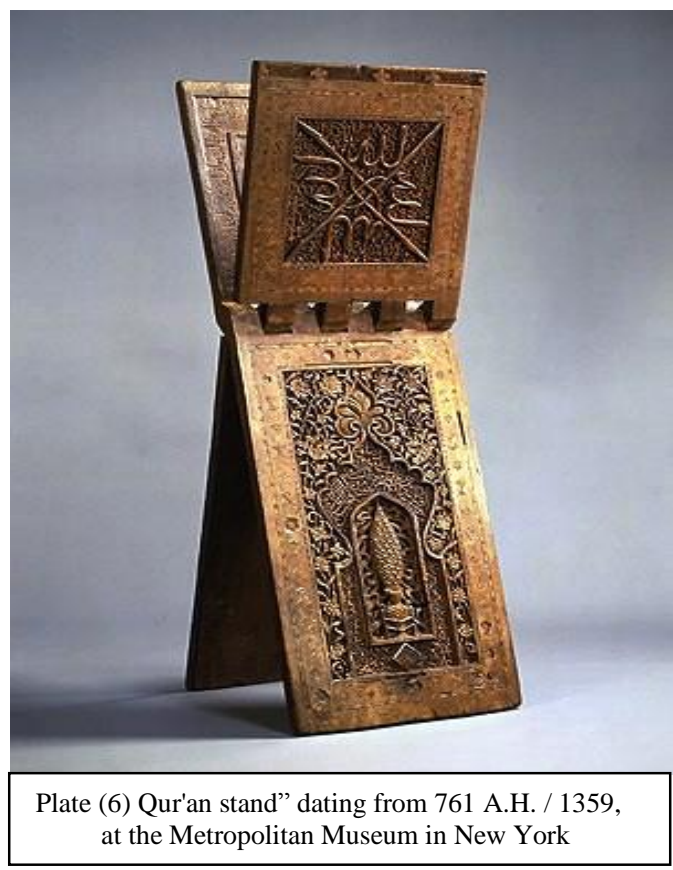

find on our in different forms, simple leaves. Simple leaves at this door took the form of small size leaf enlarges from the bottom and narrowed in upper part and ended with a pointed top, fig. (2) These leaves spread among the branches in the central panel and the lower panel of the door. Through the floral 
armaments we find a decorative form took the shape of floral bunch composed of flare leaves carried out in arranged method through them we Find tow trilogy Floral leaves. In addition, the door contains abstract Floral ornaments in Arabesque style, this ornaments composed of minute Floral branches consisted of interlaced Floral scrolls and simple multi lobed and palmettes, .fig. (3). As well as simple trilogy floral leaves, fig. (4). And other complicated leaves inside the small trilogy floral leaves beside multi-petal rosettes, fig. (5). And other took the shape of almond, resulting from two halves of palmettes adorned at the upper and the lower parts with tri-lobed floral leaf as it executed in the decorative bands which separate the panels of the door, other minute braches waved to Form interlaced circles. From them small rosettes emerged.

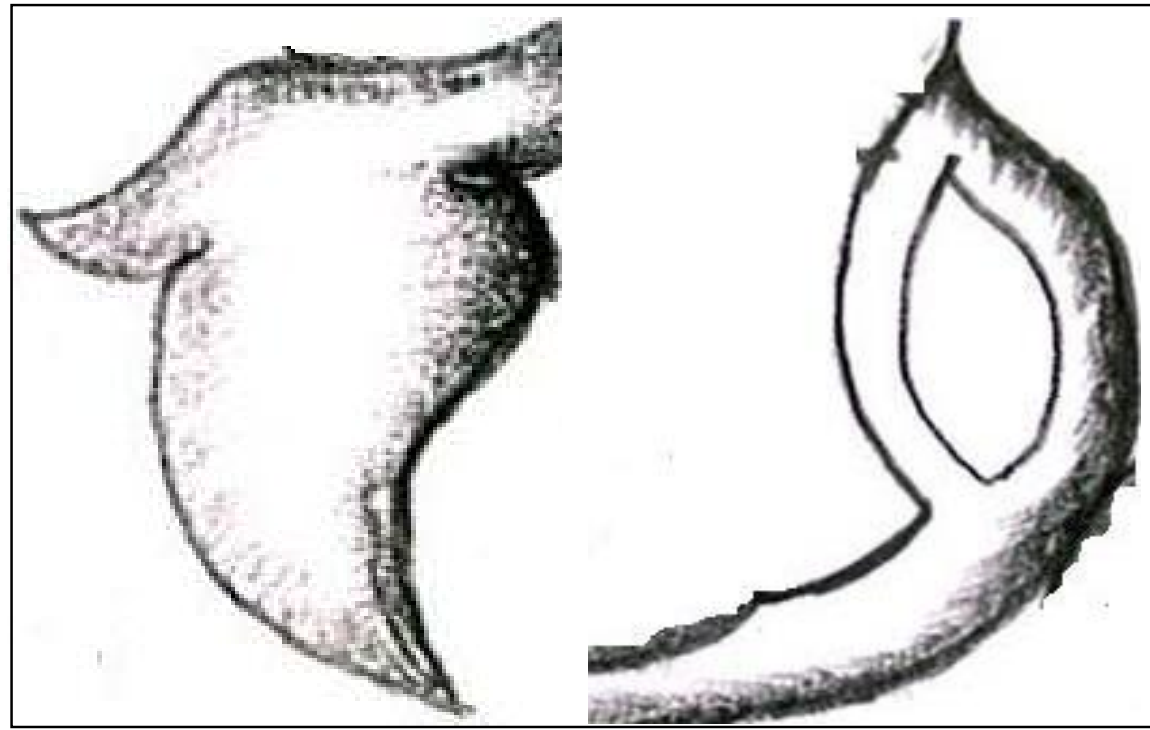

Figure (2) a simple leave at the wooden door.

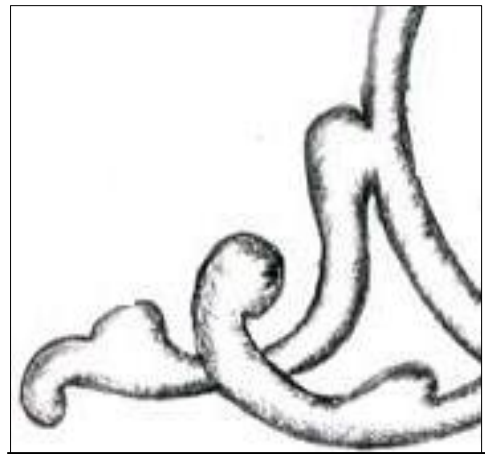

Figure (3) a simple multi lobed and palmettes.
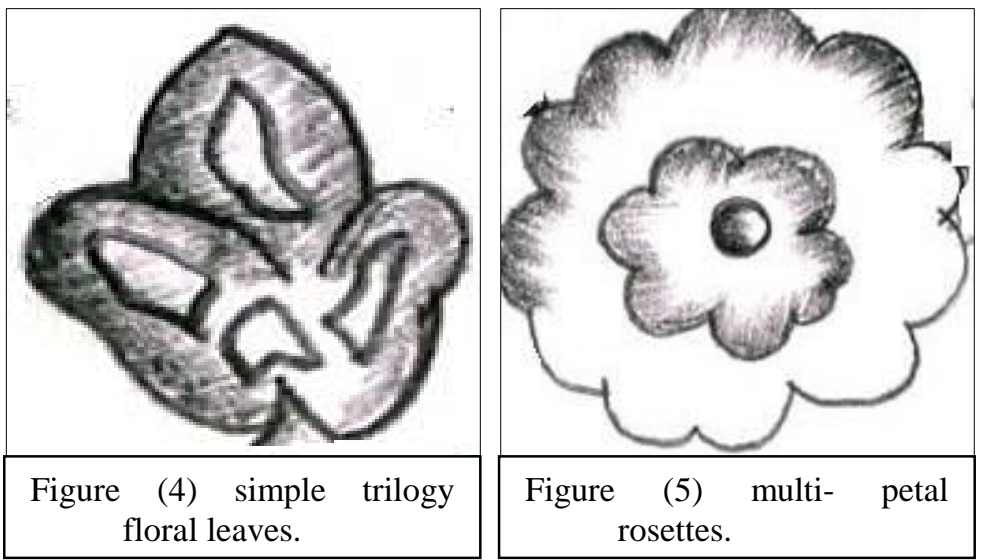

\section{Geometrical decorations in architectural form}

Among the architectural elements which commonly used for decorating the applied antiquities in Central Asia was the lobbed arch, which took various
Forms, It was composed of small arches and bows Followed each other which were seven or more and used for adorning the middle panel of the door .

\section{Conclusion}

Through the this study, it could be concluded that the same decorative elements continued for a long time before the studied door which came as a reflection of the Timurid style which characterized with the use of natural Floral ornaments as well as abstract motifs in 
Arabesque. Also, the study showed that the decorations of the door resemble the decoration of Timurid book covers for example, the use of frames which border the main decoration. And we find inside it the mixture between realistic floral ornaments and natural ones. Thus those ornament continued on the wooden artifacts "12-13A. H/ 18-19 A.D" by using the same Form and techniques which were common on the applied arts as well as the architectural buildings. Moreover, the comparison between this door and the wooden doors inside constructions in khiva we suggested that, this door can be attributed to khiva according to the similarity between its decoration and the decorations of the door existing there.

\section{References}

[1] Ministry of Culture of Uzbekistan, (2003). Islamic monuments of Uzbekistan, Tashkent.

[2] Sulaymanova, F., (1996). Navoi and Behzod, Art under the Timurids, Tashkent.

[3] Falk art of Uzbekistain, (1979). Gafur Gulyam literature art publishing house, Tashkent.

[4] Benkie. B., (1968). Quelques monuments de Bais culpte au Turkestan accidental, Ars islamica, Vol., II, pp: 69-83

[5] Demand S., (1958). Islamic Art, translated by Ahmed Essa, Dar AlMa'arf, Cairo.

[6] Smith, M.,(1938). The wood Minbar in the Masdid-I Djami, Nāīn, Ars Islamica. Vol. V (1), pp: 21-32.

[7] Abdu Rasulov, A., (1994). Khiva, Uzbeistan publisher, Tashkent.

[8] Nourmoukhammadov, N., (1980). The Mausoleum of Hodja Ahmed Yasvi, Oner Bacpace publisher, Almata.

[9] Mukminova, R., (1992).Craftsmen and Guild life in Samarqand, Timurid Art and Culture, Iran and Central Asia in the fifteenth century: in Golombek, L. \& Subtelny, (Eds.) M. studies in Islamic art and architecture, supplements to muqarnas, Vol. VI, pp: 48-66

[10] Ebaid,Sh., (2005). Drasah lenamazg mn al-tuhaf al-khashabiha al-thābetah bāmāer Asia al-wustSa fe al-fatrah mn al-karn $8 \mathrm{H}$. / 14 A.D. wahata al-karn 10 H. / 16A.D., Historical events, a referred research periodica, Journal of Center for research and historical studies, Faculty of Arts, Cairo University, pp: 162-217

[11] Crown,Y.,(1992) "Some Timurid Designs and Their Far Eastern Connections": in Golombek, L. \& Subtelny, M. (Eds)., Timurid Art and Culture. Iran and Central Asia in the Fifteenth Century, E.G.Brill, Leiden. 